found represent only the tip of the iceberg, and that more detailed searches in heavy aspen might have detected more. Do these recent nest records, part of a general southward movement across the province, after an absence of more than a century, mean that this species is now here to stay?

When Bison roamed the plains, the Common Raven was more numerous than the American Crow. ${ }^{1}$ When Thomas Blakiston of the Palliser expedition went south from Fort Carlton on a bison hunting expedition in 1858 , he found several raven nests, at least one of them beside one of the Anerley lakes (only $18 \mathrm{~km}$ south of the southern boundary of the SBA) on April 29. ${ }^{2}$

\section{Acknowledgements}

I thank Gary Bortolotti for information on the early nest attempts at the IPCO plant, Lyle and Don Doell for information and a photograph, and Stuart Houston for keyboarding and editorial assistance.

1. C. S. HOUSTON and J. K. SCHMUTZ. 1999. Changes in bird populations on Canadian grasslands. Studies in Avian Biology 18: 87-94.

2. C. S. HOUSTON. 1976. A bird watcher's outing in 1858. Saskatchewan History 29:14-25.

\title{
A MAGPIE BAND-RELEASE PROJECT IN THE CALGARY AREA, 1949
}

JIM SALT (compiler and editor), 464 Nelson Street, Victoria, BC V9A 6P4, jrsalt@Pacificcoast.net

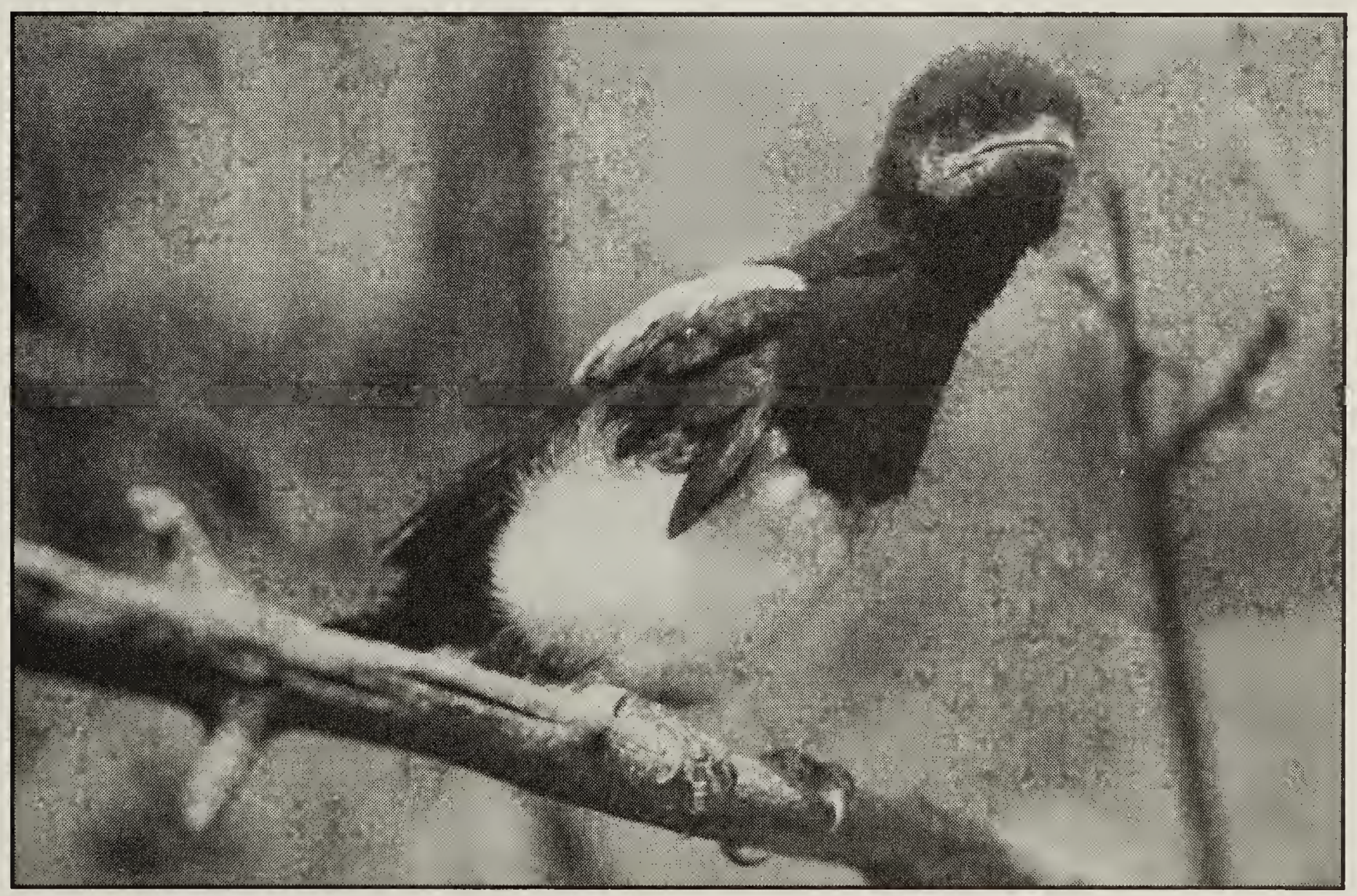


Recently, while reviewing the diaries and ornithological notes of my father, W. Ray Salt, I came upon a record of a banding project undertaken in 1948-49 in Calgary, while he was teaching biology at Mount Royal College. The project consisted of the banding and release of Black-billed Magpies and was intended to investigate aspects of behaviour, particularly dispersal and "homing" tendencies. A number of young birds and a few adults were trapped at nest localities, banded and then released at varying distances from the nest sites. As far as I am aware, the results from this work were never published. A summary of the study might be of interest to contemporary readers or workers engaged in similar experiments.

The project commenced on 28 March 1949 at a site known locally as Colpitts' hedgerows of trees or large shrubs surrounding some disused buildings on open prairie, about $25 \mathrm{~km}$ north of Calgary. Banding at this and two other sites continued for one or two days each week until 18 June 1949. The project was terminated when my family moved from the Calgary area in summer 1949.

A total of 66 birds were trapped at three nest-localities around Calgary. The majority of the magpies (50) came from Colpitts' nests, 13 were taken at a site $18 \mathrm{~km}$ west of Staveley, and three were from Rockyford, $70 \mathrm{~km}$ ENE of Calgary.

The three magpies from Rockyford were liberated at or near the nest-site. Five of the Staveley magpies were liberated near the banding site, four in downtown Calgary and four at High River. Of the 50 Colpitts' magpies, 46 were transported elsewhere, half (23) to be liberated in downtown Calgary from various prominent buildings, all sufficiently close together to be considered city-centre. Only four were released at the banding site. Table 1 gives a complete synopsis of the project by origin or nest-locality, release site and number of recoveries.

A relatively high proportion of recoveries (20 birds, 30.3\%) was obtained from this brief study. Recoveries consist of magpies identified later by band number, either by re-trapping or from bands (or bandnumbers) returned by farmers, from birds presumably shot or found dead.

The highest rate of recovery was from the magpies banded near Staveley, of which five $(38.5 \%)$ were recorded again

Table 1: Nest and release sites of banded magpies, numbers of birds from each site, distance of release-site from origin, and number of recoveries.

\begin{tabular}{|l|r|l|l|l|}
\hline Origin & No. & Released & Dist./Direction & Recovered \\
\hline Colpitts' & 23 & Calgary & $22.8 \mathrm{~km} \mathrm{~S}$ & 9 \\
\hline Colpitts' & 4 & Colpitts' & 0 & 2 \\
\hline Colpitts' & 4 & Okotoks & $56.2 \mathrm{~km} \mathrm{~S}$ & 3 \\
\hline Colpitts' & 3 & Strathmore & $47 \mathrm{ESE}$ & 0 \\
\hline Colpitts' & 3 & Baintree & $52 \mathrm{E}$ & 1 \\
\hline Colpitts' & 3 & Rockyford & $60 \mathrm{E}$ & 0 \\
\hline Colpitts' & 5 & Crossfield & $22 \mathrm{~N}$ & 0 \\
\hline Colpitts' & 5 & Brooks & $165 \mathrm{~km} \mathrm{SE}$ & 0 \\
\hline Staveley vic & 5 & Staveley & 0 & 5 \\
\hline Staveley vic & 4 & Calgary & $102 \mathrm{~N}$ & 0 \\
\hline Staveley vic & 4 & High River & $50 \mathrm{~N}$ & 0 \\
\hline Rockyford & 3 & Rockyford & 0 & 0 \\
\hline
\end{tabular}


Table 2: Release and recovery data on magpies recorded during the study.

$A$ " 0 " indicates recovery within a few kilometres of the release site.

\begin{tabular}{|l|l|l|l|l|}
\hline Released: & Date & Recovered & Dist. $(\mathbf{k m})$ & Date \\
\hline Calgary & $29 / 04$ & Calgary & 12 & $15 / 05$ \\
\hline Calgary & $28 / 03$ & Colpitts' & 22 & $11 / 06$ \\
\hline Calgary & $28 / 03$ & Bowness & 12.5 & $15 / 05$ \\
\hline Calgary & $28 / 03$ & Colpitts' & 22 & $11 / 06$ \\
\hline Calgary & $28 / 03$ & Colpitts' & 22 & $13 / 05$ \\
\hline Calgary & $28 / 03$ & Colpitts' & 22 & $11 / 06$ \\
\hline Calgary & $28 / 03$ & Colpitts' & 22 & $11 / 06$ \\
\hline Calgary & $28 / 03$ & Colpitts' & 22 & $17 / 05$ \\
\hline Calgary & $29 / 04$ & Bentley & 137 & $21 / 09$ \\
\hline Okotoks & $03 / 04$ & Twin Bridges & 36 & $06 / 06$ \\
\hline Okotoks & $03 / 04$ & Longview & 22 & $07 / 05$ \\
\hline Okotoks & $03 / 04$ & Colpitts' & 56 & $10 / 05$ \\
\hline Colpitts' & $03 / 04$ & Colpitts' & 0 & $01 / 05$ \\
\hline Colpitts' & $10 / 04$ & Colpitts' & 0 & $13 / 05$ \\
\hline Baintree & $10 / 04$ & Colpitts' & 52 & $20 / 05$ \\
\hline Staveley vic & $04 / 05$ & Staveley & 0 & $09 / 06$ \\
\hline Staveley vic & $04 / 05$ & Staveley & 0 & $17 / 06$ \\
\hline Staveley vic & $04 / 05$ & Staveley & 0 & $19 / 05$ \\
\hline Staveley vic & $04 / 05$ & Staveley & 0 & $01 / 06$ \\
\hline Staveley vic & $04 / 05$ & Staveley & 0 & $20 / 06$ \\
\hline
\end{tabular}

before the end of the study. There were fifteen recoveries of Colpitts' birds (30\%). The most distant recovery was that of a magpie released in downtown Calgary and found at Bentley, $137 \mathrm{~km}$ north, five months later. Table 2 indicates distances from release-sites to recovery sites and the time elapsed between release and recovery of each bird. These times do not necessarily indicate actual travel times, since birds recaptured or shot may have been present in an area for considerable periods before detection.

\section{Acknowledgements}

Due to the long time since this study was conducted, and the condition of records, I have been unable to identify with certainty all of the participants, and some spellings may be in error. The following individuals were identified from banding records: J. Bayuk, W. Hedley and Chris Nutter, probably of Colpitts' Farms; A. Guillemaud of Bentley; V.B. Ferguson, W.J. Ross and Percy Witt of Calgary; G. Cochlan, M. McLean and R. Perrot of Staveley; L. Wancheke of High River. Participants identified only by last name or by initials were: "G.T." of Calgary; "F.E.M." (possibly F.E. McLean of Staveley?); and Wolley-Dod (Wally Dodd?).

I am greatly indebted to Stuart Houston, and to Anna and Ted Leighton, for encouragement and editorial suggestions leading to the completion of this note. 